\title{
Perfectionism and Eating Attitudes in Portuguese University Students
}

\author{
António Macedo $^{1 *}$, Maria João Soares ${ }^{1}$, \\ Maria Helena Azevedo ${ }^{1}$, Ana Gomes ${ }^{2}$, \\ Ana Telma Pereira ${ }^{1}$, Berta Maia ${ }^{1}$ and Michele Pato ${ }^{3,4}$ \\ ${ }^{1}$ Instituto de Psicologia Médica, Faculdade de Medicina da \\ Universidade de Coimbra, Coimbra, Portugal \\ ${ }^{2}$ Departamento de Ciências da Educação, Universidade de Aveiro, Portugal \\ ${ }^{3}$ Veterans Administration, Syracuse, NY, USA \\ ${ }^{4}$ Center for Psychiatric and Molecular Genetics, SUNY/Upstate \\ Medical University, Syracuse, NY, USA
}

Objectives: The main objective was to explore which are the dimensions of perfectionism that are linked to disordered eating behaviour (EB) in a large non-clinical sample of both genders. Method: One thousand one hundred and sixty-three undergraduate students of the University of Coimbra completed the Portuguese versions of the multidimensional perfectionism scale (MPS) and the eating attitudes test (EAT-40).

Results: In both genders, the MPS total score was associated with the EAT total score and all EAT dimensions (except for socially prescribed perfectionism in females).

Self-oriented perfectionism (SOP) and socially prescribed perfectionism (SPP) were associated with EAT total score, diet concerns (DC) and bulimic behaviour (BB) in females while in males the social prescribed perfectionism (SPP) was the useful predictor of EAT total score, BB and social pressure to eat (SPE). Conclusion: These results confirm that in general high levels of perfectionism are associated with abnormal EB. This was the case for both genders for SPP but for SOP for females only. The association for other oriented perfectionism (OOP) was greater for males than for females. Copyright (C) 2006 John Wiley \& Sons, Ltd and Eating Disorders Association.

Keywords: perfectionism; personality; eating behaviour; eating disorders

\section{INTRODUCTION}

The concept of perfectionism has been a topic of increased interest in recent years. The characteristics of perfectionism have been well described by

* Correspondence to: António Macedo, Instituto de Psicologia Médica, Faculdade de Medicina de Coimbra, Rua Larga, 3004-504 Coimbra, Portugal. Fax: +351 239823170.

E-mail: amacedo@ci.uc.pt

Contract/grant sponsor: Fundação para a Ciência e Tecnologia; contract/grant numbers: POCTI/PSI/37569/2001. clinicians such as Hamachek (1978), Hollender $(1965,1978)$ and Burns (1980). Hamachek described perfectionists as people 'whose efforts-even their best ones-never seem quite good enough, at least in their own eyes. It always seems to these persons that they could-and should-do better'. Hollender drew attention to cognitive processes that maintain perfectionism such as a biased evaluation of personal standards/performance that tend to focus on flaws and discount positive achievements (selective attention). Burns (1980) saw perfectionists as 'people who strain compulsively and unremittingly toward 
impossible goals and who measure their own worth entirely in terms of productivity that keeps people in turmoil and is associated with a significant number of psychological problems'.

Some authors have suggested that perfectionism has both normal/positive and neurotic/negative aspects (Hamachek, 1978; Terry-Short, Owens, Slade, \& Dewey, 1995). According to this distinction, neurotic perfectionism is a tendency to hold and pursue unrealistically high standards/goals that is essentially motivated by a morbid inability to tolerate failure. Normal perfectionism is defined as striving for realistic standards and goals that is a function of positive reinforcement and leads to a sense of satisfaction (Terry-Short et al., 1995).

The importance of perfectionism is related to the fact that it has been linked with several psychopathological states such as depression, obsessive-compulsive-disorder, eating disorders (ED), social phobia and suicidal behaviour (Shafran \& Mansell, 2001).

Cognitive-behavioural models of perfectionism point out the self-imposed nature of demanding standards that are pursued despite significant adverse consequences, and that self-evaluation and self-worth are overly dependent on the pursuit and attainment of personal standards and upon success and achievement in a salient domain (Shafran, Cooper, \& Fairburn, 2002). Regarding the relationship between perfectionism and ED, Shafran et al. (2002) had underscored that 'self-evaluation of many people with ED can be seen as depending on their striving for personally demanding standards of control over dietary restraint, or shape or weight, despite significant adverse consequences'. Accordingly, these authors view ED as 'the expression of perfectionism in the domain of eating, shape or weight'.

\section{PERFECTIONISM AND EATING DISORDERS}

Current cognitive-behavioural models emphasise the critical role of perfectionism in the maintenance of anorexia nervosa (AN) and bulimia nervosa (BN) (Fairburn, Shafran, \& Cooper, 1999). These models point out that perfectionist's self-evaluation and self-worth are overly dependent on the pursuit and attainment of demanding personal standards and upon success and achievement in a salient domain (Shafran et al., 2002). These dysfunctional self-evaluations are based in logical errors such as dichotomous thinking, overgeneralisation, magnification and arbitrary inference. For example, it has been suggested that perfectionism and dichotomous thinking mediates the relationship between exces- sive concerns about shape and weight and rigid and intense dieting (Fairburn, 1997). So, when focused on the domain of body image/weight, perfectionism may constitute an important risk factor for abnormal eating attitudes/behaviours or full ED.

Perfectionism has been identified as a specific risk factor for the development of ED in community studies (Fairburn, Doll, Welch, Hay, Davies, \& O'Connor, 1998; Fairburn, Cooper, Doll, \& Welch, 1999). In non-clinical samples, perfectionism has been associated with disordered eating behaviours (EBs). Minarik and Ahrens (1996) found that ED symptoms were associated with two dimensions of the Frost MPS (Frost, Marten, Lahart, \& Rosenblate, 1990): concern with mistakes and doubts about actions. The study of Hewitt, Flett, and Ediger (1995) using their MPS (Hewitt \& Flett, 1991) found that self-oriented perfectionism (SOP) was related to anorexic symptoms, whereas socially prescribed perfectionism (SPP) was related to dieting, concerns with being thinner, disordered eating patterns, body image avoidance and self-esteem.

In clinical samples, early reports suggested that perfectionism was a common premorbid personality feature among patients with AN (Halmi, Goldberg, Eckert, Casper, \& Davis, 1979).

Subsequent studies, using different measures of perfectionism found higher scores of perfectionism in patients with ED compared with non-eating disordered control group (Bastiani, Rao, Weltzin, \& Kaye 1995; Bourke, Taylor, \& Crisp, 1985; Cockell, Hewitt, Goldner, Srikameswaran, \& Flett, 1996; Halmi, Sunday, Strober, Kaplan, Woodside, Fichter, Treasure, Berrettini, \& Kaye, 2000). However, there are no significant differences in perfectionism scores between subtypes of ED (Garner, Olmstead, \& Polivy, 1983; Toner, Garfinkel, \& Garner, 1986). More importantly, several studies have also shown that recovered patients maintain the high perfectionism scores, both in AN (Bastiani et al., 1995; Srinivasagam, Kaye, Plotnicov, Greeno, Weltzin, \& Rao, 1995) and BN (Stein, Kaye, Matsunaga, Orbach, Har-Even, Frank, McConaha, \& Rao, 2002). Prospective studies (Tyrka, Waldron, Graber, \& Brooks-Gunn, 2002) have shown that perfectionism seems to constitute a risk factor for the development of disordered eating attitudes along a continuum at the extreme end of which we have AN and BN. All these data suggests that perfectionism is a persistent trait which is present even in periods of symptom remission.

Given the potential risk that perfectionism might lead to developing an ED, the main objective of this study was to investigate the association of perfectionism and EB in a non-clinical Portuguese sample. 
More specifically, we attempted to gain some insight to which dimensions of this personality trait might best predict risk for development of an ED. Additionally, the literature of this topic has been mainly addressed in female samples, so we were interested in investigating the relationship of perfectionism and EB in males and between genders.

Based on the literature findings, our starting hypotheses were: (1) perfectionism is more associated with some eating factors (EAT) than others, (2) some subscales of perfectionism (MPS) may be associated with abnormal eating attitudes/behaviours. Furthermore, we hope to gather preliminary data on any gender differences that might exist between the sexes both in perfectionism and eating attitudes, as measured by the MPS and the eating attitudes test (EAT) respectively, as well as any correlations that might exist.

\section{METHOD}

\section{Participants}

The data for this report were drawn from an ongoing research on perfectionism and obsessive-compulsive spectrum disorders (FCT-POCTI/37569/PSI/ 2001), which was approved by the Medical Ethics Review Committee, of the University Hospital of Coimbra, Portugal (Macedo, Pocinho, Soares, Dourado, Campos, Domingues, \& Azevedo, 2002).

The sample comprised 1163 university undergraduate students of the Faculty of the Medicine, and Humanities of University of Coimbra, aged between 17 and 25 years. Excluded were 35 subjects with ages upper 25 years old, due to the low prevalence of these ages in the sample (descriptive data is presented on Table 1). Males and females mean age was respectively 19.7 $(\mathrm{SD}=1.68)$ and $19.3(\mathrm{SD}=1.54)$. Based on self-reports of weight and height, the women's mean body mass index was 20.9 $(\mathrm{SD}=2.3)$ and the men's was $22.7(\mathrm{SD}=2.6)$. The mean weight, height and BMI were significant higher in males than in females.

\section{Procedures}

Consent was obtained from all participants and, after that each subject completed the Portuguese versions of the EAT-40 (Garner \& Garfinkel, 1979) and MPS (Hewitt \& Flett, 1991).

\section{Multidimensional Perfectionism Scale-MPS (Hewitt \& Flett, 1991)}

The Hewitt and Flett (MPS; Hewitt \& Flett, 1991) was used to measure the 3 dimensions of perfectionism:

(1) Self-oriented perfectionism (SOP)_intrapersonal component, which involves perfectionist behaviours deriving from and directed to the self.

(2) Social prescribed perfectionism (SPP)—interpersonal dimension that involves the perception that others significant hold excessively high standards and expectations of perfection for oneself.

(3) Other-oriented perfectionism (OOP)—interpersonal component which involves perfectionist standards and demands deriving also from the self, but which are imposed on others.

The scale has 45 items, and the subject is asked to rate each item on a 7 -point scale ranging from strongly disagree (score 1), to strongly agree (score 7).

In its Portuguese version (Soares, Gomes, Macedo, Santos, \& Azevedo, 2003) the MPS total score, derived from the sum of scores for the individual, showed a high internal consistency (Cronbach's alpha $=0.884)$, and the test-retest reliability over 4 weeks $(N=293)$ was 0.843 (Pearson $r, p=0.000)$. Theoretically the scores may range from 1 to 315 . A higher score is considered as an indicator of higher levels of perfectionism. The factor analysis showed

Table 1. Description of the sample

\begin{tabular}{lccc}
\hline & Males $N=399$ & Females $N=764$ & Total Sample $N=1163$ \\
& $34.3 \%$ & $65.7 \%$ & $N(\%)$ \\
\hline Age (years)* & $N(\%)$ & $N(\%)$ & $19.5 \pm 1.60$ \\
Mean \pm SD & $19.7 \pm 1.68^{*}$ & $19.3 \pm 1.54^{*}$ & $17-25$ \\
Range & $17-25$ & $17-25$ & $1151(99.0 \%)$ \\
Marital status & & & $6(0.5 \%)$ \\
Single & $394(98.7 \%)$ & $5(0.7 \%)$ & $6(0.5 \%)$ \\
Married & $1(0.3 \%)$ & $2(0.3 \%)$ & $21.5 \pm 2.6 ; 15.8-33.4$ \\
NI & $4(1 \%)$ & $20.9^{*} \pm 2.3 ; 15.8-32.9$ & \\
BMI (Mean \pm SD; range)* & $22.7^{*} \pm 2.6 ; 17.3-33.4$ & & \\
\hline
\end{tabular}

NI, No information; M, mean; SD, standard deviation; BMI, weight $(\mathrm{kg}) /$ height $(\mathrm{m})^{2}$; ${ }^{*}$ gender significant differences, student $t$-test, $p=0.000$. 
the same three factors of the original version (shown above) which explained $33.18 \%$ of the total variance. The internal consistency (Cronbach's alpha) for the subscales were: SOP (18 items) $=0.893$; SPP $(15$ items $)=0.842 ;$ OOP $(8$ items $)=0.663$ (all values were those obtained for the female sample).

Eating Attitudes Test-Garner and Garfinkel (1979)

The EAT-40 (Garner \& Garfinkel, 1979) was used to measure the eating attitudes and behaviours, and particularly the following three dimensions:

(1) Diet concerns (DC): labelled dieting by Garner, Olmsted, Bohr, and Garfinkel (1982), includes items about food, diet and body weight concerns, about the preoccupation with being thinner, the fear of fatness, the 'fattening food' avoidance and the engagement in dieting behaviour and in exercise as a strategy to burn calories.

(2) Bulimic behaviour (BB): labelled bulimia and food preoccupation by Garner et al. (1982), related to a persistent preoccupation with food, overeating episodes and self-imposed measures to mitigate the 'fattening' effects of food like the vomiting after meals and the laxatives abuse.

(3) Social pressure to eat (SPE): this dimension is labelled oral control by Garner et al. (1982) and consists of items reflecting the perceived preoccupation from others with thinness and the perceived pressure imposed by others to gain weight.

The EAT-40 is a 40-item self report likert questionnaire, and subjects were required to judge if the item is applied 'never', 'rarely', 'sometimes', 'often', 'very often' or 'always'.

The EAT-40 has been translated and validated by the authors in a subsample of 596 females undergraduate students (Soares, Macedo, Gomes, \& Azevedo, 2004). A good internal consistency was found (alfa Cronbach $=0.863$ ) and also a good testretest reliability $(r=0.857 ; p<0.01)$. The factor analysis showed three factors which explained $33.65 \%$ of the total variance (DC; BB; SPE).

Since we were interested in the analysis of EB in both genders, the EAT validation methodology was de novo and independently applied to a male $(N=399)$ and a larger female $(N=764)$ sample. The scoring system used was the one that was applied by Garner and Garfinkel (1979) with scores from 0 to 3 (less extreme responses- 'never', 'rarely' and 'some times' scored as ' 0 '). Theoretically the scores may range from 0 to 120 . A higher score is considered as an indicator of more disturbance in eating attitudes and behaviours.
The factor analysis revealed three factors in the female sample and also in total sample (explaining, respectively, $28.60 \%, 28.78 \%$ of the total variance) and four factors in the male sample (explaining $34.66 \%$ of the total variance). In males, the BB was sub divided in two factors (Purgative behaviours and Binge Eating).

The internal consistency of EAT was also good for total sample and for females and acceptable for males (Cronbach alpha of 0.799 for total sample, of 0.795 for females and of 0.694 for males) and the test-retest reliability indicated a temporal stability of EAT scores (Spearman coefficients: $\mathrm{r}_{\mathrm{s}}=0.736$ in total sample, $r_{\mathrm{s}}=0.780$ in females and $r_{\mathrm{s}}=0.683$ in males; with $p=0.000$ in all cases).

\section{Statistical Analyses}

All statistical analyses were performed with SPSS, version 12.0, for Windows (Copyright, SPSS Inc., 1989-2003).

The reliability study and the factor analysis of MPS and EAT were performed in the total sample and also in female and male sub samples. No gender differences were found in MPS factor dimensions. However, due to the fact that a gender difference in EAT factor structure was found, results were analysed in the total sample $(n=1163)$ and also in female and male samples, as independent samples. Basic frequency data were compiled, followed by the study of EAT and MPS dimensions scores relationships, using the Pearson product-moment correlation. Following Cohen criteria (1992) for correlation levels analysis, a correlation of 0.10 was considered poor, a correlation of 0.30 was medium and a correlation of 0.50 was high. A multiple regression analysis was conducted to predict the EB from the MPS dimensions scores, with the three perfectionism dimensions entered as predictors, and eating dimensions and total scores entered as dependent variables.

Continuous variables were compared using independent-sample $t$ test or the variance analysis (oneway ANOVA) as appropriate. Complementary to the variance analysis the indicated multiple comparisons tests were performed.

\section{RESULTS}

\section{Perfectionism and Eating Behaviour}

Scores distribution of the MPS and EAT dimensions are presented in Table 2. Considering the eating scores in total sample, significant gender differences 
Table 2. Means on MPS and EAT dimensions

\begin{tabular}{lcc}
\hline & $\begin{array}{c}\text { Males } \\
\text { Mean } \pm \text { SD (range) }\end{array}$ & $\begin{array}{c}\text { Females } \\
\text { Mean } \pm \text { SD (range) }\end{array}$ \\
\hline EAT & & $3.9 \pm 5.00(0-29)$ \\
Diet concerns & $3.6 \pm 2.63(0-19)$ & - \\
Bulimic behaviour-purge & $0.2 \pm 1.08(0-16)$ & - \\
Bulimic behaviour-binge eating & $0.1 \pm 1.41(0-10)$ & $0.5 \pm 1.50(0-19)$ \\
Bulimic behaviour & $1.4 \pm 2.17(0-21)$ & $0.4 \pm 1.16(0-8)$ \\
Social pressure to eat & $8.5 \pm 5.59(1-51)$ & $10.7 \pm 7.72(0-62)$ \\
Total score & & \\
MPS & $83.6 \pm 16.90(20-126)$ & $86.0 \pm 16.26(33-124)$ \\
Self-oriented perfectionism & $46.3 \pm 11.09(17-87)$ & $44.5 \pm 11.95(15-94)$ \\
Social prescribed perfectionism & $45.0 \pm 7.24(18-63)$ & $39.1 \pm 6.48(20-56)$ \\
Other oriented perfectionism & $187.4 \pm 27.78(97-265)$ & $184.6 \pm 26.83(102-264)$ \\
Total Score & & \\
\hline
\end{tabular}

$\mathrm{SD}$, standard deviation.

were found in $\mathrm{DC}(p=0.000), \mathrm{BB}(p=0.015)$ and EAT total score $(p=0.000)$; which were significantly higher in females than in males. Regarding the perfectionism scores, the social prescribed perfectionism (SPP) was significantly higher in males than in females $(p=0.012)$.

We investigated the relation between perfectionism and EB dimensions, using the Pearson moment-product correlations followed by multiple regression analysis, separately in females and males. In male sample, to increase gender comparability, a composite factor was calculated (BB), resulting from the sum of both BB dimensions items (purging behaviour and binge eating).

We found significant Pearson correlations between EAT and MPS total scores in both samples (in females $r=0.302$ in males $r=0.240$; in both $p<0.01$ ). Considering the correlations between MPS total score and EAT dimensions we found that the significant and positive correlations ranged from $0.206(\mathrm{BB})$ to $0.306(\mathrm{DC})$ in females and from 0.137 (SPE) to 0.171 (BB) in males $(p<0.01$ in all cases). No significant correlations were observed between MPS total score and SPE in females $(r=0.033, p=0.373)$.

To investigate the relationship between each perfectionism dimension and EB dimensions and total score, Pearson moment-product correlations and partial correlations were computed (Table 3).

- In females DC, BB factors and EAT total score were positive and significantly correlated with selforiented perfectionism (SOP) and socially prescribed perfectionism (SPP). No significant correlations were found between MPS dimensions and social pressure to eat (SPE).

A multiple regression analysis was conducted with the three predictor perfectionism variables

Table 3. Correlation coefficients and partial correlations between EAT and MPS dimensions scores in females and males

Perfectionism

Eating behaviour scores (EAT)

\begin{tabular}{|c|c|c|c|c|c|c|c|c|}
\hline & \multicolumn{2}{|c|}{ Diet concerns } & \multicolumn{2}{|c|}{ Bulimic behaviour } & \multicolumn{2}{|c|}{ Social pressure to eat } & \multicolumn{2}{|c|}{ Total scale } \\
\hline & $r$ & Partial $r$ & $r$ & Partial $r$ & $r$ & Partial $r$ & $r$ & Partial $r$ \\
\hline \multicolumn{9}{|l|}{ Females } \\
\hline Self-oriented & $0.301^{* *}$ & $0.224^{* *}$ & $0.162^{* *}$ & $0.078^{*}$ & 0.038 & 0.029 & $0.288^{* *}$ & $0.203^{* *}$ \\
\hline Social prescribed & $0.235^{* *}$ & $0.114^{* *}$ & $0.257^{* *}$ & $0.190^{* *}$ & 0.045 & 0.024 & $0.264^{* *}$ & $0.150^{* *}$ \\
\hline Other oriented & 0.021 & -0.025 & $-0.074^{*}$ & -0.068 & -0.026 & -0.030 & -0.007 & -0.037 \\
\hline \multicolumn{9}{|l|}{ Males } \\
\hline Self-oriented & $0.128^{*}$ & 0.048 & $0.138^{* *}$ & 0.065 & 0.072 & -0.001 & $0.186^{* *}$ & 0.081 \\
\hline Social prescribed & $0.106^{*}$ & 0.072 & $0.161^{* *}$ & $0.119^{*}$ & $0.213^{* *}$ & $0.197^{* *}$ & $0.203^{* *}$ & $0.153^{* *}$ \\
\hline Other oriented & $0.129^{*}$ & 0.095 & 0.062 & 0.024 & -0.022 & -0.030 & $0.116^{*}$ & 0.069 \\
\hline
\end{tabular}

${ }^{*} p<0.05 ;{ }^{* *} p<0.01 ; r$ : Pearson moment-product correlation coefficients; bulimic behaviour in males (sum of purging behaviour and binge eating factors items). 
entered as one set of predictors and with the EAT dimensions as dependent variables. Results showed that the combined perfectionism dimensions explained $10.1 \%$ of the total variance of DC (adjusted $\left.r^{2}=0.101 ; F(3,689)=26.744, p=0.000\right), 7.0 \%$ of the total variance of the BB (adjusted $r^{2}=0.70$; $F(3,362)=4.0, p=0.000)$ and $10.5 \%$ of the total variance of the EAT total score (adjusted $r^{2}=0.105$; $F(3,672)=27.183, p=0.000)$. The three perfectionism measures were not significantly related to SPE $(F(3,690)=0.773, p=0.509)$.

Considering the partial correlation coefficients we found that only the SOP and the SPP were useful predictors of the total variance of $\mathrm{DC}, \mathrm{BB}$ and $E A T$ total in females $(p<0.01)$ (Table 3$)$.

- In males DC and EAT total score were significantly correlated with all perfectionism dimensions. As in females, the BB was significantly correlated with SOP and SPP. The SPE was correlated with the SPP.

The multiple regression analyses, using as predictors the three perfectionism dimensions and as criterion variable the EAT dimensions and total score, indicated that the combined perfectionism dimensions explained $2.2 \%$ of total variance of DC (adjusted $\left.r^{2}=0.021 ; \quad F(3,364)=3.570, p=0.014\right)$, $2.5 \%$ of total variance of BB (adjusted $r^{2}=0.025$, $F(3,362=4.068, p=0.007), 3.9 \%$ of SPE (adjusted $\left.r^{2}=0.039 ; F(3,364)=5.865, p=0.001\right)$ and $5.1 \%$ of the total variance of EAT total score (adjusted $\left.r^{2}=0.051, F(3,357)=7.438, p=0.000\right)$.

Partial correlation coefficients showed that only the SPP dimension was correlated with BB, SPE and the EAT total scores. On the basis of these correlational analysis we can conclude that the useful predictor of the BB, SPE and EAT total in males was the SPP $(p<0.05$ for BB and $p<0.01$ for the other two dimensions). A trend to a significant contribution of the OOP in DC was observed in males $(p=0.071)$.

However, judgements about the relative importance of these three MPS predictors are difficult, because they are significantly correlated (except for SPP which was no significantly correlated with OOP in males: $r=0.024, p=0.640$ ). Coefficients ranged from -0.101 to 0.432 in females, and from 0.381 to 0.406 in males (all $p<0.01$ ). The correlations between SOP and SPP were the strongest.

Next, we analysed perfectionism differences between groups with distinct eating attitudes and behaviours. Participants were distributed in four groups based on EAT total score quartiles values (Table 4). Assuming that higher EAT scores are related to a more disturbed EB, the variations between levels of perfectionism in EB groups were investigated with the variance analysis (One-Way ANOVA) and the adequate post-hoc multiple comparisons test (Bonferroni).

Table 4. MPS scores (Mean; SD) and EAT groups in females, males and total samples

\begin{tabular}{|c|c|c|c|c|c|c|c|}
\hline \multirow{2}{*}{$\begin{array}{l}\text { Perfectionism } \\
\text { scores (MPS) }\end{array}$} & \multicolumn{6}{|c|}{ EAT groups } & \multirow[t]{2}{*}{ Group comparisons (a) } \\
\hline & $\begin{array}{c}\text { Group } 1 \\
\text { (low) M (SD) }\end{array}$ & $\begin{array}{l}\text { Group } 2 \\
M(S D)\end{array}$ & $\begin{array}{l}\text { Group } 3 \\
\text { M (SD) }\end{array}$ & $\begin{array}{c}\text { Group } 4 \\
\text { (high) M (SD) }\end{array}$ & $\begin{array}{c}\text { One-Way } \\
\text { ANOVAF (df) }\end{array}$ & $p$ & \\
\hline \multicolumn{8}{|l|}{ Female } \\
\hline Self-oriented & $81 \pm 16$ & $84 \pm 15$ & $85 \pm 16$ & $93 \pm 16$ & $18.29(698)$ & 0.000 & $4>1^{* * *}, 2^{* * *}, 3^{* * *}$ \\
\hline Social prescribed & $41 \pm 11$ & $44 \pm 11$ & $44 \pm 12$ & $48 \pm 13$ & 10.07 (699) & 0.000 & $4>1^{* * *}, 2^{* *}, 3^{*}$ \\
\hline Other oriented & $39 \pm 6$ & $39 \pm 7$ & $40 \pm 6$ & $39 \pm 7$ & $0.41(711)$ & $0.748^{\S}$ & - \\
\hline Total score & $176 \pm 26$ & $182 \pm 25$ & $185 \pm 26$ & $196 \pm 25$ & $16.65(665)$ & 0.000 & $4>1^{* * *}, 2^{* * *}, 3^{* *} ; 3>1^{*}$ \\
\hline \multicolumn{8}{|c|}{$\begin{array}{llll} & 1 \\
\end{array}$} \\
\hline Self-oriented & $78 \pm 16$ & $82 \pm 18$ & $83 \pm 17$ & $90 \pm 15$ & $8.30(366)$ & 0.000 & $4>1^{* * *}, 2^{* *}, 3^{*}$ \\
\hline Social prescribed & $43 \pm 11$ & $47 \pm 10$ & $46 \pm 11$ & $49 \pm 11$ & $4.81(370)$ & 0.003 & $4>1^{* *}$ \\
\hline Other oriented & $43 \pm 7$ & $45 \pm 7$ & $45 \pm 7$ & $47 \pm 7$ & $3.34(377)$ & 0.020 & $4>1^{*}$ \\
\hline Total Score & $176 \pm 27$ & $186 \pm 28$ & $187 \pm 26$ & $199 \pm 25$ & $10.61(352)$ & 0.000 & $4>1^{* * *}, 2^{* *}, 3^{*} ; 3>1^{*}$ \\
\hline \multicolumn{8}{|l|}{ Total } \\
\hline Self-oriented & $76 \pm 16$ & $78 \pm 15$ & $81 \pm 15$ & $86 \pm 16$ & $21.70(1069)$ & 0.000 & $4>1^{* * *}, 2^{* * *}, 3^{* * *}$ \\
\hline Social prescribed & $42 \pm 11$ & $44 \pm 11$ & $45 \pm 11$ & $48 \pm 12$ & $13.29(1074)$ & 0.000 & $4>1^{* * *}, 2^{* * *}, 3^{* *}$ \\
\hline Other oriented & $44 \pm 7$ & $44 \pm 7$ & $45 \pm 7$ & $45 \pm 7$ & $2.33(1091)$ & $0.072^{\S}$ & - \\
\hline Total score & $177 \pm 27$ & $181 \pm 26$ & $185 \pm 25$ & $196 \pm 26$ & $23.87(1021)$ & 0.000 & $4>1^{* * *}, 2^{* * *}, 3^{* * *} ; 3>1^{*}$ \\
\hline
\end{tabular}

Group 1, EAT total score < percentile 25; Group 2, EAT total score between percentiles 25 and 50; Group 3, EAT total score between percentiles 50 and 75; Group 4, EAT total score $\geq$ percentile 75.

${ }^{*} p<0.05 ;{ }^{* *} p<0.01 ;{ }^{* * *} p=0.000$; ${ }^{\S}$ No significant; (a) comparisons made using Bonferroni multi comparisons test. 
Significant differences $(p<0.01)$ in SOP, SPP and MPS total mean scores were found between the subgroups of EAT, in female, male and total samples.

An increasing of SOP and MPS total mean scores were observed through the EAT subgroups, in all samples (Table 4). However, only the subgroup 4, with highest eating scores (EAT $\geq$ P75) had significantly higher SOP and MPS mean scores than the other EAT subgroups, in total and gender samples (Table 4). The subgroup 4 (EAT $\geq$ P75) also had significantly higher SPP mean scores than the others EAT subgroups in females and total samples. In males this subgroup only differed in the SPP from the lowest EAT subgroup (EAT $<$ P25).

Significant differences were also found between group 3 (P50-P75) and group $1(\mathrm{EAT}<\mathrm{P} 25)$, for MPS total score, in all samples.

The Significant OOP mean differences were only found in male sample, where the subgroup 4, with more disturbed eating attitudes and behaviours $(E A T \geq P 75)$ scored higher than the group 1, with less eating problems $($ EAT $<$ P25) (Table 4).

\section{DISCUSSION}

Most of the studies to date that have investigated the association between perfectionism and EB used only female samples. To our knowledge, the present investigation is the first to study this association in both genders in a non-clinical large sample of Portuguese undergraduate students.

The results of our study both confirm that perfectionism is a multidimensional concept and that higher levels of perfectionism are related with abnormal EB. In both genders, the MPS total score is associated with the EAT total score and with all EAT dimensions (except for SPE, in females).

Concerning the perfectionism dimensions SPP was important in the explanation of the variance of eating attitudes and behaviours in both males and females. Additionally SOP was also a relevant predictor of disordered behaviour, in females. The results in our female sample are similar with those studies that used exclusively females, like the study of Hewitt et al. (1995). A new finding from our study, not reported previously is the possible contribution of other oriented perfectionism to the EB in males.

The relation between eating concerns and high levels of SOP is not surprising and for some authors SOP is the dimension considered more closely related to the concept of clinical perfectionism (Shafran et al., 2002). Perfectionist demands and self-imposed standards may be expressed in several life domains, one of which may be body image, which is a crucial component of self-concept. So, weight and body image may be the target of perfectionistic tendencies which leads the individual to strive for a perfect appearance. It has been suggested that this pressure to have the perfect body is especially felt by females, and this may constitute one of the reasons for the SOP gender difference that we found in our study. However, the role of SOP in clinical perfectionism is not entirely clear. In opposition to Shafran et al. (2002), other authors (Dunkley, Blankstein, Masheb, \& Grilo, 2006) argued that factor analytic studies of the subscales from the Hewitt and Flett (H-MPS, 1991) and Frost et al. (F-MPS, 1990) have consistently yielded two higher order factors: personal standards (PS) and evaluative concerns (EC). PS involves the setting of high standards and goals for oneself and is related with the subscales SOP from the H-MPS and PS from the F-MPS; EC involves critical evaluations of one's own performance and chronic concerns about other's criticism and expectations and is related with SPP from the H-MPS and doubts about actions and concerns over mistakes from the F-MPS.

The critical issue for Dunkley et al. (2006) is that possessing high PS is not by itself maladaptative and that PS perfectionism measures are weakly related to psychopathology, in the literature. In contrast, EC measures have been consistently associated to depressive and anxiety symptoms (Dunkley et al., 2006) and these results underscore that the selfcritical evaluative tendencies associated with EC measures, namely SPP, are more relevant to clinical perfectionism and its association with psychopathology. Our results showing that disturbed EB is associated with SPP in both genders, are in line with this conceptualisation that stresses the importance that interpersonal aspects of perfectionism have in self-evaluative processes. Previously, the role of interpersonal aspects of perfectionism has been incorporated in several models of ED behaviours (Heatherton \& Baumeister, 1991) and some authors like Bruch (1981) has underlined that interpersonal perfectionism play an important etiological role in ED. On the other hand it has been stressed that sociocultural pressure in the area of physical appearance may constitute an important environmental risk factor for the development of EB behaviours. In this societal context, the association between SPP and EB here reported, could be a reflection of cultural pressures to conform with unrealistic body image ideals. 
One of the potential weaknesses of this study is that we have twice as many women as men. However, we think that this fact does not reflect any bias in the sense that women were more eager in reporting their problems, but only represent the fact that more women are enrolled at the university, specially in the field of humanities. Another possible shortcoming is that the EAT has been constructed for females and may not be the more suitable instrument to measure disordered EB in men. However there is no agreement of which is the more adequate instrument for this purpose, due to the fact that there is no specific instrument for male assessment in this research area.

It is important to look at and continue to investigate perfectionistic traits. More evidence in this area may help us learn how to pinpoint these perfectionistic tendencies before they develop into pathological behaviour as a mean to target ED before they occur and develop preventive strategies directed to the modification of the perfectionistic cognitive processes/behaviours.

\section{ACKNOWLEDGEMENT}

Work supported by the grant POCTI/PSI/37569/ 2001 from the Fundação para a Ciência e Tecnologia.

\section{REFERENCES}

Bastiani, A., Rao, R., Weltzin, T., \& Kaye, W. (1995). Perfectionism in anorexia nervosa. International Journal of Eating Disorders, 17, 147-152.

Bourke, M., Taylor, G., \& Crisp, A. (1985). Symbolic functioning in anorexia nervosa. Journal of Psychiatric Research, 19, 273-278.

Bruch, H. (1981). Conversations with anorexics. New York: Basic Books.

Burns, D. (1980). The perfectionist's script for self defeat. Psychology Today, 34, 51.

Cockell, S., Hewitt, P., Goldner, E., Srikameswaran, S., \& Flett, G. (1996). Levels of perfectionism among women with anorexia and bulimia nervosa. Poster presented at the 26th International Congress of Psychology, Montreal, Quebec, Canada.

Cohen, J. (1992). A power primer. Psychological Bulletin, $112,155-159$.

Dunkley, D., Blankstein, K., Masheb, R., \& Grilo, C. (2006). Personal standards and evaluative concerns dimensions of "clinical" perfectionism: A reply to Shafran et al. (2002, 2003) and Hewitt et al. (2003). Behaviour Research Therapy, 44, 63-84.
Fairburn, C. (1997). Eating disorders. In D. M. Clark, \& C. G. Fairburn (Eds.), Science and practice of cognitive behaviour therapy (pp. 209-241). Oxford: Oxford University Press.

Fairburn, C., Cooper, Z., Doll, H., \& Welch, S. (1999). Risk factors for anorexia nervosa: Three integrated case control comparisons. Archives of General Psychiatry, 56, 468-476.

Fairburn, C., Doll, H., Welch, S., Hay, O., Davies, B., \& O'Connor, M. (1998). Risk factors for binge eating disorder: A community based, case control study. Archives of General Psychiatry, 55, 425-432.

Fairburn, C., Shafran, R., \& Cooper, Z. (1999). A cognitive behavioural theory of anorexia nervosa. Behaviour Research and Therapy, 37, 1-13.

Frost, R., Marten, P., Lahart, C., \& Rosenblate, R. (1990). The dimensions of perfectionism. Cognitive Therapy and Research, 14, 449-468.

Garner, D., Olmstead, M., \& Polivy, J. (1983). The Eating Disorder Inventory: A measure of cognitivebehavioural dimensions of anorexia nervosa and bulimia. In P. Darby, D. Garfinkel, D. Garner, \& D. Coscina (Eds.), Anorexia nervosa: Recent developments in research. New York: Alan R. Liss.

Garner, D. M., \& Garfinkel, P. E. (1979). The Eating Attitudes Test: An index of symptoms of anorexia nervosa. Psychological Medicine, 9, 273-279.

Garner, D. M., Olmsted, M. P., Bohr, Y., Garfinkel, P. (1982). The Eating Attitudes Test: Psychometric features and clinical correlates. Psychological Medicine, 12, 871-878.

Halmi, K., Goldberg, S., Eckert, E., Casper, R., \& Davis, J. (1979). Unique features associated with age of onset of anorexia nervosa. Psychiatry Research, 1, 209-215.

Halmi, K., Sunday, S., Strober, M., Kaplan, A., Woodside, D., Fichter, M., Treasure, J., Berrettini, W., \& Kaye, W. (2000). Perfectionism in anorexia nervosa: Variation by clinical subtype, obsessionality, and pathological eating behaviour. American Journal of Psychiatry, 157, 1799-1805.

Hamachek, D. (1978). Pyschodinamics of normal and neurotic perfectionism. Psychology, 15, 27-33.

Heatherton, T., \& Baumeister, R. (1991). Binge eating as escape from self-awareness. Psychological Bulletin, 110, 86-108.

Hewitt, P., \& Flett, G. (1991). Perfectionism in the self and social contexts: Conceptualization, assessment, and association with psychopathology. Journal of Personality and Social Psychology, 60, 456-470.

Hewitt, P., Flett, G., \& Ediger, E. (1995). Perfectionism trait and perfectionistic self-presentation in eating disorder attitudes, characteristics, and symptoms. International Journal of Eating Disorders, 18, 317-326.

Hollender, M. (1965). Perfectionism. Comprehensive Psychiatry, 6, 94-103.

Hollender, M. (1978). Perfectionism, a neglected personality trait. Journal of Clinical Psychiatry, 39, 384.

Macedo, A., Pocinho, F., Soares, M. J., Dourado, A., Campos, C., Domingues, O., \& Azevedo, M. H. (2002). Perfeccionismo-uma dimensão fenotípica comum aos fenómenos obsessivos e distúrbios alimentares? Psiquiatria Clínica, 23, 163-174. 
Minarik, M., \& Ahrens, A. (1996). Relations of eating and symptoms of depression and anxiety to the dimensions of perfectionism among undergraduate women. Cognitive Therapy and Research, 20, 155-169.

Shafran, R., \& Mansell, W. (2001). Perfectionism and psychopathology: A review of research and treatment. Clinical Psychology Review, 21, 879-906.

Shafran, R., Cooper, Z., \& Fairburn, C. (2002). Clinical perfectionism: A cognitive-behavioural analysis. Behaviour Research Therapy, 40, 773-791.

Soares, M., Gomes, A., Macedo, A., Santos, V., \& Azevedo, M. H. (2003). Escala Multidimensional de Perfeccionismo: Adaptação à População Portuguesa. Revista Portuguesa de Psicossomática, 5, 46-55.

Soares, M., Macedo, A., Gomes, A., \& Azevedo, M. H. (2004). A Versão Portuguesa do Teste de Atitudes Alimentares-40. Psiquiatria Clínica, 25, 5-19.

Srinivasagam, N., Kaye, W., Plotnicov, K., Greeno, C., Weltzin, T., \& Rao, R. (1995). Persistent perfectionism, symmetry and exactness in anorexia nervosa and obsessive-compulsive disorders. American Journal of Psychiatry, 152, 1630-1634.

Stein, D., Kaye, W., Matsunaga, H., Orbach, I., Har-Even, D., Frank, G., McConaha, C., \& Rao, R. (2002). Eatingrelated concerns, mood, and personality traits in recovered bulimia nervosa subjects: A replication study. International Journal of Eating Disorders, 32, 225229.

Terry-Short, L., Owens, R., Slade, P., \& Dewey, M. (1995). Positive and negative perfectionism. Personality and Individual Differences, 18, 663-668.

Toner, B., Garfinkel, P., \& Garner, D. (1986). Long-term follow-up of anorexia nervosa. Psychological Medicine, $48,520-529$.

Tyrka, A., Waldron, I., Graber, J., \& Brooks-Gunn, J. (2002). Prospective predictors of the onset of anorexic and bulimic symptoms. International Journal of Eating Disorders, 32, 282- 290. 